\title{
Integrating Business Intelligence And Decision Focused Database Methods: A Prescriptive Principles Approach
}

\author{
Michael C. Tolman, Utah State University, USA \\ David H. Olsen, Utah State University, USA \\ Meghan N. Lewis, Utah State University, USA
}

\begin{abstract}
Inasmuch as the field of Management Information Systems has seen significant changes, business school curriculums have not kept pace with the growing demands in the market. This approach closes that gap between the needs of the market and the products, or students, universities are supplying. Using Prescriptive Principles, this module gives students a business question to be answered, has the instructor demonstrate SQL functions and querying techniques, sets the scene for the students to reflect on the application of this business intelligence project, encourages students to use their previous experience to develop a business strategy to utilize the insight gained from their developed SQL functions, and finally sets up a frame work whereby their findings can be presented to their peers, as business "stakeholders," and demonstrate their new understanding. Such a method will create students capable of understanding code, but more so, it will create students who will understand how that code can help sustain a business's growth strategy and its bottom-line.
\end{abstract}

Keywords: Business Intelligence; Business Analytics; Data Analytics; Decision Support Systems; Management Information Systems Project Tutorial; Instructional Strategies; Teaching/Learning Methods; SQL; Prescriptive Principles; Customer Loyalty; Collaborative Learning; Peer-to-Peer Collaboration

\section{INTRODUCTION}

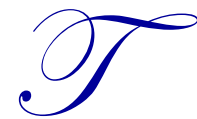

he field of Management Information Systems has seen a number of remarkable innovations in the last few decades. From floppy discs, to laser discs, CDs to DVDs, and now "cloud" computing, our attention has shifted somewhat from increasing our ability to store data to increasing our ability to analyze that data. Elbashir, Collier, and Sutton proposed, "The ability for the average user to extract relevant data without the aid of specialized applications is limited," despite the interactivity of various databases. They go on to say that while they are commercially available, tools for Business Intelligence are not easily understood (Elbashir, Collier, \& Sutton, 2011). System and Database Administrators are less concerned today with space limitations on servers or execution times on massive queries, as they are preoccupied with the methodology by which terabytes upon terabytes of decades of transactional data can be sorted and made relevant through detailed and thorough analysis. It is in this challenging climate that students and professionals alike have a significant burden of mastering these skills and implementing them in real-world applications in a world that has little patience for "learning curves."

These business intelligence (BI) professionals seek to make better and faster business decisions based on their ability to utilize vast amounts of accumulated data (Chaudhuri, Dayal, \& Narasayya, 2011; Fouché \& Langit, 2011). Significant improvements to business processes and decision-making have been widely reported by organizations from a diverse range of industries (Chaudhuri et al., 2011; Laursen \& Thorlund, 2010; Turban, Sharda, Dursun, \& King, 2010; Turban, Sharda, \& Denlen, 2011). As such, the growth of business intelligence has dramatically increased the demand for workers with advanced analytical skills. However, the supply of such skilled 
workers appears weak and suggests an impending shortage of analytical talent (Accenture, 2007; Manyika et al., 2011). In fact, the McKinsey Global Institute forecasts a 50 to 60 percent gap between the supply and demand of people with deep expertise in data analysis, equaling 140,000 to 190,000 unfilled positions by 2018 (Manyika et al., 2011). Such a gap would indicate that university business programs have not kept pace with market demands (Connolly, 2012; Sircar, 2009; Wixom et al., 2011).

Furthermore, it behooves educators and business leaders to find techniques to better expose and train their students and employees in business intelligence concepts and practices throughout their course of study (Connolly, 2012; Conway \& Vasseur, 2009; Sircar, 2009; Wixom et al., 2011). While online resources and tutorials are legion, business schools must alter what they teach in order to prepare qualified graduates in the area of business intelligence and analytics (Connolly, 2012; Conway \& Vasseur, 2009; Sircar, 2009; Watson, 2008; Wixom et al., 2011) and apply the latest breakthroughs to instructional design and learning methods to facilitate stronger technical skills and foster a deeper understanding of BI principles. Wixom and her colleagues recommend providing opportunities for students to solve meaningful problems framed in current business contexts and to "find ways to share teaching materials" (2011, p. 308).

The University of Arizona offers two courses in BI, focusing on various topics such as social media, dimensional modeling, ETL, and data staging, to name a few. However, Arizona takes their instruction one step further by showing their students how to 1) gather strategic decision-making requirements from business, 2) develop key performance indicators (KPIs), 3) learn corporate performance management metrics using a Balanced Scorecard, and 4) design and implement business dashboards" (University of Arizona MIS Department, 2011). It is with that purpose that the authors propose the following general method by which future business intelligence analysts may gain not only an understanding of concepts and principles, but also a practical application of said concepts and principles. To do this, this article advocates that business schools 1) form meaningful partnerships between the university and business leaders in the community, 2) provide a symbiotic relationship in which businesses receive a cost-effective solution to meaningful, "real-world" problems solved by students, and 3) teach in such a way to close the gap between the theory of the classroom and its application in the business world. Through such teaching methods, students will gain a stronger knowledge of the application of data analysis techniques and substantial experience in discovering solutions to current business intelligence problems.

\section{LITERATURE REVIEW}

Over the years, BI has come to mean a variety of different things to different people. Davenport defines it as an advantageous implementation of "decision support technologies for the enterprise aimed at enabling knowledge workers, such as executives, managers, and analysts, to make better and faster decisions" (Davenport, 2006). Moreover, others describe BI as developing technologies to "tame information," to leverage and extract value from data, and to create new roles in the organization to handle new business needs (Gantz \& Reinsel, 2011). Regardless of its definition, Business Intelligence has become the newest and strongest currency in the global economy, affecting all sectors from small business to international conglomerates.

This trend is also seen internationally as well. Regarding BI in Slovenia, Lukmana and Associates remarked, "For companies working in highly competitive and information-intensive industries, BI is critical for understanding business operations, increasing customer satisfaction, and taking advantage of new opportunities" (Lukmana, Hackney, Popovič, Jaklič, \& Irani, 2011). In other words, every key performance indicator affecting a business' success is dependent upon their ability to successfully deploy information systems strategies that will capitalize upon the hidden gems business intelligence professionals can mine out of their data.

Gantz and Reinsel noted, after mentioning the fact that in 2011 the amount of information created and replicated will surpass 1.8 zettabytes, "While $75 \%$ of the information in the digital universe is generated by individuals, enterprises have some liability for $80 \%$ of the information in the digital universe at some point in its digital life." They mention that BI tools are increasingly dealing with data in real-time, such as "adjusting insurance premiums based on where people drive, routing power through the intelligent grid, or changing marketing messages on the fly based on social networking responses" (Gantz \& Reinsel, 2011). Such intelligent solutions for business problems can only come about through an understanding of how to turn data analysis into business insight. 
This need for solutions and the possibilities that an enterprise's data holds is a significant resource that has largely been left on a shelf for years. However, from 2005 to 2011, there has been a significant shift in investments by enterprises in data analysis. Gantz and Reinsel (2011) noted that in the same time period, over $\$ 4$ trillion was invested by enterprises on hardware, software, services, and staff to manage and leverage returns on investments in this burgeoning field of business intelligence and analysis (Gantz \& Reinsel, 2011). Continental Airlines is one such company that has seen a significant return on their investment, reporting an ROI of more than 1000 percent on a $\$ 30$ million investment of its BI infrastructure (Anderson-Lehman, Waton, Wixom, \& Hoffer, 2004).

More generally, a study in 2006 showed that the average return on all BI projects was 310 percent (Lonnqvist \& Pirttimaki, 2006). Regardless of where one finds oneself in an organization, their success is largely dependent upon their ability to leverage their enterprise's data. Gantz and Reinsel observed,

The success of many enterprises in the coming years will be determined by how successful CIOs are in driving the required enterprise-wide adjustment to the new realities of the digital universe. (Gantz \& Reinsel, 2011)

Understandably, ROI is not a new concept to business professionals. However, leveraging data and data science to find new revenue streams and to connect with new markets is an opportunity that will be ignored at an enterprise's peril.

However, despite these significant investments and the change in culture regarding data and data science, some enterprises are still not receiving the ROI that they would have expected from BI. Giniat noted, "More than 50 percent of BI projects fail to deliver the expected benefit" and "seven of ten executives say they do not get the right information to make business decisions" (Giniat, 2011). One might conclude that BI is not providing the returns promised by researchers, analysts, and industry prognosticators. The question might be, given the need for BI, the ease of storage for data, and the increased potential for processing and analysis, "What is missing from the equation that is limiting the impact of BI for these enterprises?"

Information Systems professionals, from data analysts to CIOs, must be able to manage emerging BI opportunities. Business schools have made adjustments to their curriculum, with over 53 percent offering new or enhanced coursework in BI and analytics (Wixom, 2012). That said, 45 percent of schools surveyed remarked that their biggest challenge is getting access to data sets (Wixom, 2012). For that reason, it is the authors' intention that the work here might serve as a case study in which students are provided with real data from a real company and where they are able "to understand business needs, interpret the analyses performed . . . and provide leadership for data-informed decision-making in their organization" (Gantz \& Reinsel, 2011).

\section{METHODS}

Using the Microsoft SQL Server Development Environment, this business intelligence project tutorial will expose students to a few relatively simple SQL functions and how their application can answer key questions for important business decision-makers. Designed to be an in-class activity in any university database course, this module will demonstrate one method to enhance raw data and to turn it into something actionable, with authentic customer loyalty data from an online retailer. This data has been made anonymous and contain transactional information from a major online retailer who has sales across a diverse host of websites.

This raw data will allow students to have experience with loading data into a database, performing queries, writing triggers and stored procedures, and finally, answering questions about the potential impact of these procedures on the business at large. The exact data set used in this tutorial is available for download on the Utah State University Business Intelligence Research Group's website by following the link in the Appendix.

The content of this project utilizes M. David Merrill's five prescriptive instructional principles to better represent the new "post-industrial paradigm" (Reigeluth, 2012) in instructional theory. In his article, Reigeluth proposes Merrill's principles as a necessary remedy to a problem that he describes stems from society's needs transitioning from the industrial age to the information age. Reigeluth argues that traditional instructional methodologies were developed at a time when the education system was "designed more for sorting than for 
learning" (Reigeluth, 2012). The traditional "sage on a stage" education model should have little place in our classrooms and Reigeluth proposes more of a "guide on the side" approach that would be more appropriate for business schools in our information age.

As such, this tutorial will focus on task-centered learning, where students will "involve learning by doing, utilize tasks that are of inherent interest to the learner . . . and offer opportunities for collaboration" (Reigeluth, 2012). This tutorial and teaching methodology have been tested and successfully implemented in various upper division university database courses. The authors would encourage, however, that information systems educators modify this tutorial and find authentic data that will suit the needs of their students, their individual teaching preferences, and their course learning objectives.

\section{Project Tutorial Description}

Research has shown that "learning a skill is facilitated to the extent that instruction tells the students how to do it, shows them how to do it for diverse situations, and gives them practice with immediate feedback, again from diverse situations" (Merrill, 1983; Merril, Reigeluth, \& Faust, 1979). Following Merrill's five prescriptive instructional principles, this project tutorial will present the following methodology: give students a business question to be answered, have the instructor demonstrate SQL functions and querying techniques, set the scene for the students to reflect on the application of this business intelligence project, encourage students to use their previous experience to develop a business strategy to utilize the insight gained from their developed SQL functions, and finally to set up a frame work whereby their findings can be presented to their peers, as business "stakeholders," where they can demonstrate their new understanding.

\section{Task-Centered Principle}

The key aspects to look for in this stage of the learning module are that there should be a strong focus on a task-centered strategy in the instruction and that the instruction should go forward with increasing complexity. Additionally, the tasks should be atomic in that they are self-contained and whole iterations that contribute to accomplishing the entire project. This will enable the students to immediately immerse themselves in the relevancy of the project at hand. The instructor should conduct a discussion to build a framework wherein students can understand the context of the business intelligence and data analytics and SQL tools they will utilize in the project.

As such, the instructor-led discussion should utilize online, in course textbooks, and/or personal experience in the industry. The instructor should strive to find current and relevant examples of the application of the tools that will be discussed to gain the students attention. Once gained, the instructor can describe the learning objective of the project. The presentation of these objectives should be done is such a way that will enable the students to easily read and retrieve during the presentation and to be able to refer back to them throughout the course of the project.

The following is a list of objectives to consider throughout the entire project; however, instructors should feel free to revise or add any of these objectives to their own preferences:

- $\quad$ Demonstrate proficiency in using tools in the Microsoft SQL Server Development Environment and provide meaningful analysis, utilizing specifically:

○ Data modeling concepts (Normalization)

- SELECT, INSERT, UPDATE, CREATE statements

- Stored Procedures

- SQL Triggers

- Understand the importance of business intelligence and data analytics to business decision-makers and its business applications to enterprises in this ever-changing, data-centric information age

- Integrate past experiences and knowledge in other business areas with new business intelligence principles learned in this module to develop a business strategy utilizing insights gained from developed SQL functions

- $\quad$ Present findings to project stakeholders to demonstrate mastery of SQL functions and to demonstrate a deep understanding of how this business intelligence project fits into the larger picture of the enterprise's business objectives 
After this discussion, the instructor should lay out the expectations for each of the remaining four stages of the learning module. At the end of each stage, students should be expected to demonstrate proficiency in each of the aspects outlined and will be evaluated accordingly. This will encourage active participation of students throughout the module and engaged learning of the outlined principles.

\section{Demonstration Principle}

In this portion of the instruction, the instructor should start with a demonstration of SQL functions. This is meant to "provide a demonstration of the skill consistent with the type of component skill: kinds-of, how-to, and what-happens" (Reigeluth, 2012). Testing experience with this module has shown that peer demonstration is particularly effective, especially in technology-enabled classrooms. Some information systems classes are taught in computer labs, but it has be the authors' observations that having technology so close at hand - the temptation to check Facebook or Reddit - can prove to be too much for some students. Therefore, to better engage students, turning off lab computers and relying solely on the main computer and having students rotate turns at the keyboard "driving" the demonstration can have a significant impact on student engagement and knowledge retention.

The following is an exercise that will give students exposure to CREATE, INSERT, SELECT, and UPDATE statements and will enable them to set up dataset necessary for their business intelligence project. The authors would suggest that the instructor start with a discussion of data modeling while displaying the following data model found in Figure 1 in the Appendix. This discussion might include principles such as entity relationships, normalization, query optimization, nomenclature guidelines, syntax and other topics germane to the instructors experience, research, and overall learning objectives of the course.

After the discussion, the class will move to a peer demonstration of SQL techniques. While some students may have had exposure to structured querying language, the authors will go through this tutorial as though this is a student's first time using SQL in the Microsoft SQL Server Management Studio. Prior to this discussion, the instructor should set up a database for the class or for each individual student, whichever the instructor prefers. The instructor should only have one screen available for students to observe and should invite a student to come to the front of the class to operate the computer and to "drive" the discussion for the class.

Once SQL Server Management Studio is running (Figure 2 in the Appendix), the instructor can then have another student come to the front of the class and allow the previous student to sit down. By rotating through each of the students in the class, the instructor ensures that each student remains engaged since they may be called upon next to take over for their colleague. Additionally, the instructor can encourage participation by recruiting help by his or her colleagues for the student in the "hot-seat," as every student would likely have varying levels of proficiency with SQL. This activity should be repeated through all of the CREATE TABLE steps found in Figure 3 in the Appendix.

Next, the instructor can use the data found at https://www.huntsman.usu.edu/bigroup/htm/projects/prescriptive-principles-module to populate the insert statements needed to populate the Customers and Websites Tables (Figure 4 in the Appendix). This could include a discussion about ETL and how businesses manage their data transfer processes.

After populating these tables, the instructor can demonstrate how to test for data integrity through simple SELECT, COUNT, COUNT (DISTINCT $\mathrm{x}$ ), SELECT TOP $\mathrm{x}$, and why it might be important to not perform a SELECT $*$ on a massive dataset. Then the instructor can lead a discussion on Procedures, their importance and utilization in databases, and why they are important to the development of this particular customer loyalty tool.

Finally, the class can move towards the development of the trigger. It should be noted that the instructor should try to avoid copying and pasting code. In many interviews for Database Administrators, Business Intelligence Analysts, and other Information Systems development positions, a trend toward the interviewers requesting applicants to demonstrate proficiency by writing code out by hand has been noticed. Having students copy and paste code would be a disservice to their professional development and would inhibit their ability to find positions after graduation. A focus should be placed on teaching them the nomenclature, structure, and syntax of SQL and then have them develop their ability to speak in that language. Figure 5 in the Appendix shows an example of the code 
used for the trigger, but again, it is stressed that the instructor should encourage students to write out their own queries and even improve on what is shown here in this module.

The final step in the Demonstration Phase of this tutorial is to create the procedure that will update the customer's loyalty status in the database, as seen in Figure 6 in the Appendix.

\section{Application Principle}

The main goal of this phase is to provide intrinsic or corrective feedback that should decrease as the phase progresses to encourage better application for the students. Whereas prior to this phase, students took turns in inclass peer demonstrations of querying techniques, this phase will focus on engaging students in peer-collaboration. The key learning outcome should be an understanding of the importance of business intelligence and data analytics to business decision-makers and its business applications to enterprises.

To do this, the instructor will revisit the topic of business intelligence and data analytics. After a short overview, students will split up into groups and each group will discuss the potential impact of the past activities on a business and how such work can be beneficial to an enterprise's bottom-line. Following are a few key questions students should answer:

- Why is customer loyalty important to a business?

- What would be the best way to convey information derived from the procedures and triggers created to key decision-makers in the organization that may or may not have any knowledge or experience with database principles or interpreting raw data?

- Why would the format of your data presentation be an important aspect of your position as a data analyst?

- How would storytelling techniques help you present your data?

- What strategies would you suggest for the business to increase customer loyalty based on the data insights you have found?

- How could you measure the successful implementation of your business strategies?

The instructor should feel free to change or add to this list to best suit the scope of their individual classes and the individual needs and interests of their students.

\section{Activation Principle}

In this phase, the instructor will lead a discussion with regard to why IT projects fail. A good resource for this is The Real Business of IT: How CIOs Create and Communicate Value by Richard Hunter and George Westerman printed by the Harvard Business School Press. The purpose of this is to "integrate new knowledge in learners' cognitive structures by having them recall, describe, or demonstrate relevant prior knowledge or experience" (Reigeluth, 2012). Also, as part of this discussion, the instructor encourages students to share their previous experiences with one another and to have them add the new insights they have gained about business intelligence and data analysis to their existing framework of strategic thinking as it applies specifically to business.

\section{Integration Principle}

The final phase of this learning module seeks to integrate their new knowledge by having students reflect on and present their new knowledge and skills in a Findings Report to be presented to the entire class. This public demonstration of their new knowledge and skill is in accordance with Reigeluth's final principle of integration (Reigeluth, 2012). In this Findings Report, students will be expected to discuss and defend their new knowledge and skills in regards to business intelligence, data analytics, and application of such techniques to an enterprise's business strategy. Students should engage in some form of peer-critique, either through formal written peer evaluations or a discussion of one another's findings.

The Findings Report should be a summarized description of the database model, tables, procedures, and triggers that were created. Students should then present their findings and note interesting trends that they were able 
to find in their exploration and analysis of the data. Finally, students should create and explore possible applications of those insights to apply the skills gained and to understand how the execution of those skills fits into the larger picture of the enterprise's business objectives. It is the authors' hope that such a Findings Report and Presentation will encourage students to understand the role that BI has within an organization and to understand the effect it can have on an enterprises bottom-line by being able to sort through a seemingly insurmountable amount of data.

\section{CONCLUSION}

Data analysis has historically been constrained by storage capabilities and processing power. Over recent years, these constraints have eased their grip on analysis and have forged a new world in which the limitations on analysis rest mainly on an individual analysts' ability to utilize the many tools at their disposal. Going forward, institutions of higher education must find a way to give their students real and relevant experience using widely adopted and cutting edge BI tools and techniques, with a deep understanding of analytical methods to find actionable insight for businesses and institutions.

This paper demonstrates a practical and pertinent module with direct application to a business question that applies to many industries that track customer loyalty and buying habits. Such triggers could be used with data visualization tools and lead to a tablet or mobile application for key decision-makers in executive level roles in marketing or finance. Through the development of this trigger, students are exposed to principles that illustrate the impact of a relatively simple SQL script and how, when applied to raw data, this script can help decision makers maximize their enterprise's profitability.

While the authors acknowledge that this is but one possible application of BI techniques, continued research is certainly warranted with regard to developing other creative and practical approaches to making data analysis and BI a significant part of a business school's curriculum. Additionally, it is recommended that universities place a determined focus on collecting relevant data sets for students with which students may be able to work and to practice. Such efforts would not only increase the value of their student's experience, but would also create mutually beneficial relationships with community and business leaders. Such relationships would most certainly lead to increased placement and to a better reputation for that institution's alumni.

\section{AUTHOR INFORMATION}

Michael Tolman is a Master of Science candidate for Management Information Systems and Business Administration at Utah State University. He has worked in customer service, sales, and management for over 10 years in diverse industries ranging from retail to renewable energy. He has been instrumental in developing improving the Business Intelligence Research Group and has been awarded several scholarships for his accomplishments and his leadership in the MIS Department and the Huntsman School of Business. Currently, he is in an internship with Oracle under the Director of Customer Experience, providing data mining and analysis services. E-mail: michaelctolman@gmail.com

David Olsen is the Management Information Systems Department Head at Utah State University. He received his Ph.D. in Management Information Systems from The University of Arizona in 1993 and taught at The University of Akron accounting department in accounting information systems for five years. Dr. Olsen focuses his teaching primarily in areas of database management. His research interests include database concurrency control, accounting information systems, the integration of SQL, XML and XBRL, and database modeling. His research has been published in journals such as Communications of the ACM, Issues in Accounting Education, and the Journal of Database Management. E-mail: david.olsen@usu.edu (Corresponding author)

Meghan Lewis is pursuing a Bachelor of Science degree in Management Information systems at Utah State University. She has worked as a Project Coordinator, ordering supplies, scheduling outside vendors and services, and tracking progress, costs, and deadlines. She enjoys working in a team environment and has developed a strong ability to accomplish the tasks given to her and to solve difficult problems. Meghan has worked with the USU Business Intelligence Research Goup and has throroughly enjoyed gaining a deep understanding of data analytics and business intelligence concepts. She is expecting to graduate from USU in Summer of 2013. 


\section{REFERENCES}

1. Accenture. (2007). Cultivating high performance through information management. Retrieved from http://www.meritalk.com/uploads_legacy/whitepapers/AIMSCIOSurvey.pdf

2. Brock, W., Lakonishok, J., \& LeBaron, B. (1992). Simple technical trading rules and the stochastic properties of stock returns. The Journal of Finance, 47(5), 1731-1764.

3. ChartSchool. (2012). Moving averages - simple and exponential. Retrieved from http://stockcharts.com/school/doku.php?id=chart_school:technical_indicators:moving_averages

4. Chaudhuri, S., Dayal, U., \& Narasayya, V. (2011). An overview of business intelligence technology. Communications of the ACM, 54(8), 88-98.

5. Chen, H., Chiang, R. H. L, \& Storey, V. C. (2010). Business intelligence research. MIS Quarterly, 34(1), 201-203.

6. Connolly, D. (2012). Why b-schools should teach business intelligence. Bloomberg Businessweek. Retrieved from http://www.businessweek.com/articles/2012-04-23/why-b-schools-should-teach-businessintelligence

7. Conway, M., \& Vasseur, G. (2009). The new imperative for business schools. Business Intelligence Journal, 14(3), 13-17.

8. Fouché, G., \& Langit, L. (2011). Foundations of SQL server 2008 R2 business intelligence (2 ${ }^{\text {nd }}$ ed.). New York, NY: Apress.

9. Gagné, R. M., Briggs, L. J., \& Wager, W. W. (1992). Principles of instructional design (4th ed.). Belmont, CA: Wadsworth/Thomson.

10. IBM. (2009). The new voice of the CIO: Insights from the global chief information officer study. Retrieved from http://www-304.ibm.com/businesscenter/cpe/download0/183490/MM_CIO_Study.pdf

11. IEEE (2011). Gagne's nine events. Retrieved from https://www.ieee.org/publications_standards/publications/subscriptions/prod/mdl/gagnes_nine_events.html

12. Laursen, G. H. N., \& Thorlund, J. (2010). Business analytics for managers: Take business intelligence beyond reporting. Hoboken, NJ: John Wiley and Sons.

13. Liu, G. (2008). Innovating research topics in learning technology: Where are the new blue oceans? British Journal of Educational Technology, 39(4), 738-747.

14. Luftman, J., \& Ben-Zvi, T. (2010). Key issues for IT executives 2009: Difficult economy's impact on IT. MIS Quarterly Executive, 9(1), 49-59.

15. Manyika, J., Chui, M., Brown, B., Bughin, J., Dobbs, R., Roxburgh, C., \& Hung Byers, A. (2011). Big data: The next frontier for innovation, competition, and productivity. McKinsey Global Institute: McKinsey and Company. Retrieved from

http://www.mckinsey.com/Insights/MGI/Research/Technology_and_Innovation/Big_data_The_next_fronti er_for_innovation

16. Pettey, C., \& Goasduff, L. (2011). Gartner executive programs worldwide survey of more than 2,000 CIOs identifies cloud computer as top technology priority for CIOs in 2011. Stamford, CT: Gartner Research.

17. Reisslein, J., Seeling, P., \& Reisslein, M. (2005). Computer-based instruction on multimedia networking fundamentals: Equational versus graphical representation. IEEE Transactions on Education, 48(3), 438447.

18. Sircar, S. (2009). Business intelligence in the business curriculum. Communications of the Association for Information Systems, 24(17), 289-302.

19. Topi, H., Valacich, J., Wright, R., Kaiser, K., Nunamaker, J., Sipior, J., \& de Vreede, G. (2010). IS 2010: Curriculum guidelines for undergraduate degree programs in information systems. Communications of the Association for Information Systems, 26(18), 359-428.

20. Turban, E., Sharda, R., \& Denlen, D. (2011). Decision support and business intelligence systems $\left(9^{\text {th }}\right.$ ed.). Upper Saddle River, NJ: Pearson Prentice Hall.

21. Turban, E., Sharda, R., Dursun, D., \& King, D. (2010). Business intelligence: A managerial approach (2 ${ }^{\text {nd }}$ ed.). Upper Saddle River, NJ: Pearson Prentice Hall.

22. Watson, H. J. (2008). Business schools need to change what they teach. Business Intelligence Journal, 13(4), 4-7.

23. Williams, S. (2011). 5 barriers to BI success and how to overcome them. Strategic Finance, 93(1), 27-33. 
24. Wixom, B., Ariyachandra, T., Goul, M., Gray, P., Kulkarni, U., \& Phillips-Wren, G. (2011). The current state of business intelligence in academia. Communications of the Association for Information System, 29(16), 299-312.

25. Zhu, P., \& St. Amant, K. (2010). An application of Robert Gagné's nine events of instruction to the teaching of website localization. Journal of Technical Writing and Communication, 40(3), 337-362. 


\section{APPENDIX}

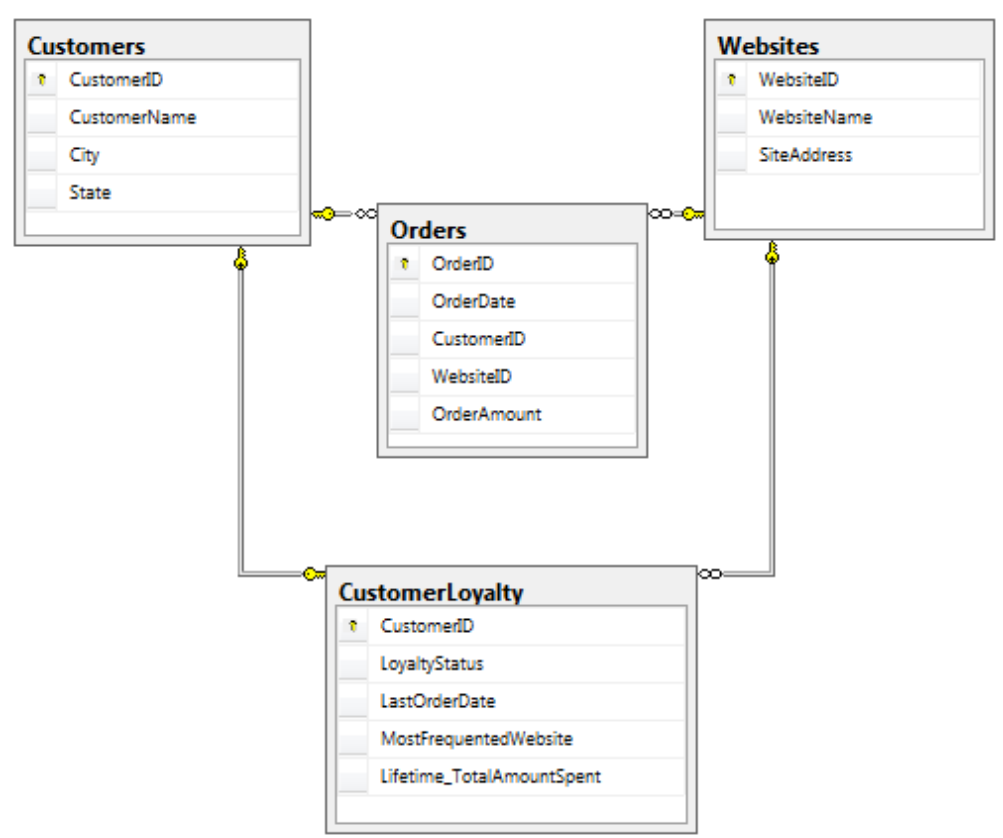

Figure 1: Data Model for Customer Loyalty BI Project

Connect to SQL Server Management Studio

1. Click Start

2. Open the Microsoft SQL Server 2012 folder

3. Click SQL Server Management Studio

4. On the Connect to Server page, choose Database Engine as the Server type

5. Enter the Server name and Authentication Information for your server

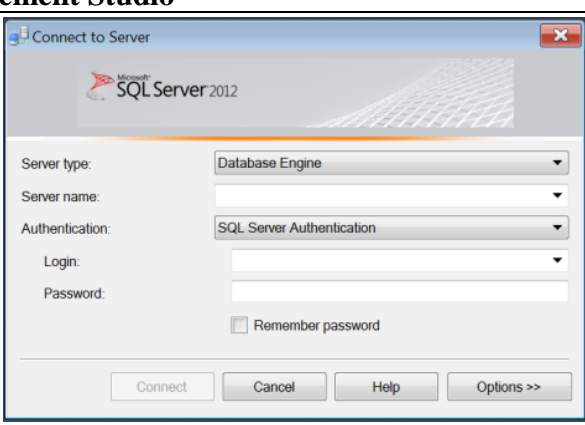

Figure 2: Connecting to SQL Server Management Studio 


\begin{tabular}{|c|c|}
\hline \multicolumn{2}{|c|}{ Create Tables } \\
\hline 1. Click New Query from the toolbar. & 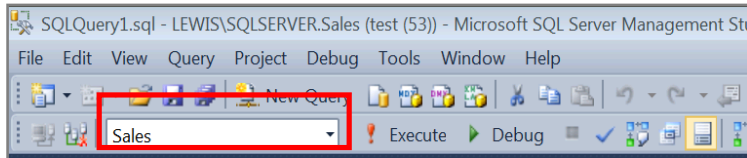 \\
\hline $\begin{array}{l}\text { 2. Choose your database from the dropdown menu on } \\
\text { the SQL Editor toolbar. }\end{array}$ & 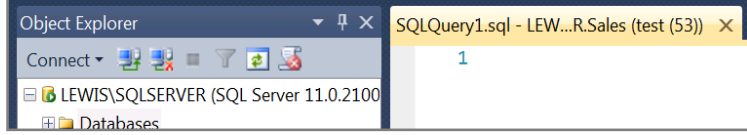 \\
\hline
\end{tabular}

1. In the Query Editor Window, enter the Create Table Statement shown below.

2. Click Execute to add the Customers table to your database.

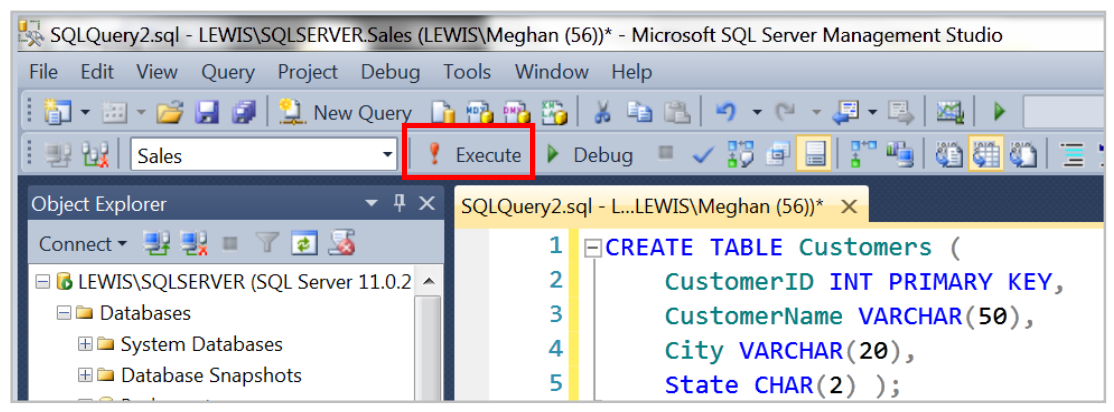

3. Repeat steps 3 and 4, using the Create Table Statements below, to add the remaining three tables.

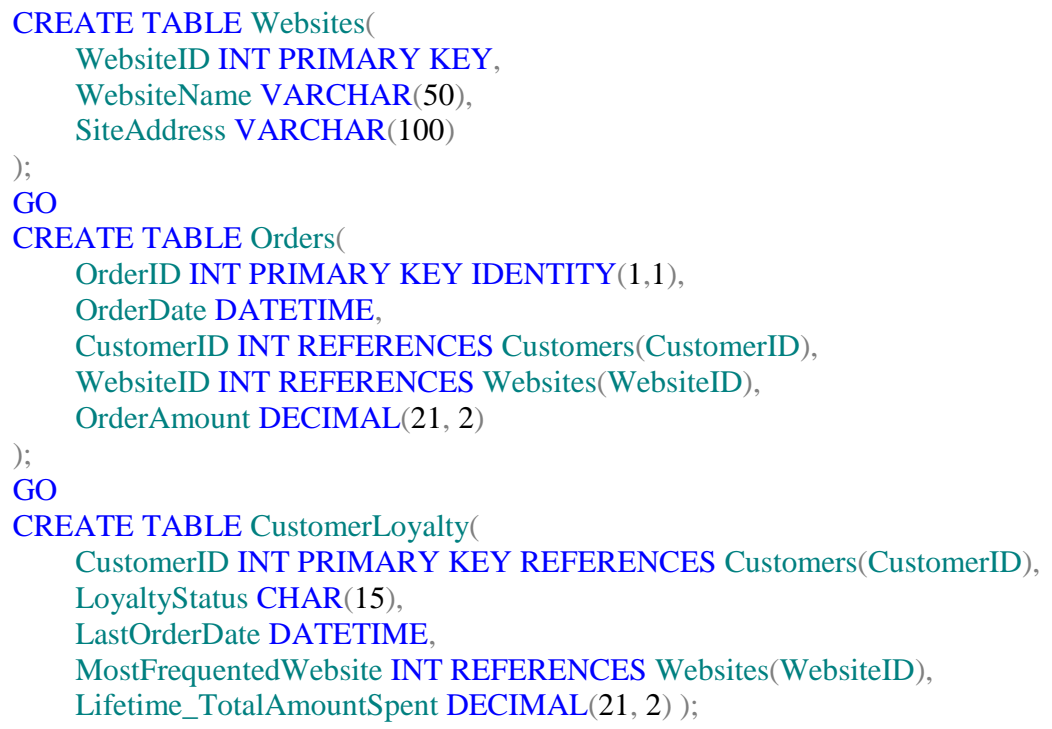

Figure 3: Creating Tables 


\section{Figure 3: Creating Tables cont.}

1. The Object Explorer on the left side of the screen can be used to view the tables in your database.

- $\quad$ Expand (+) your database

- $\quad$ Expand the tables tab

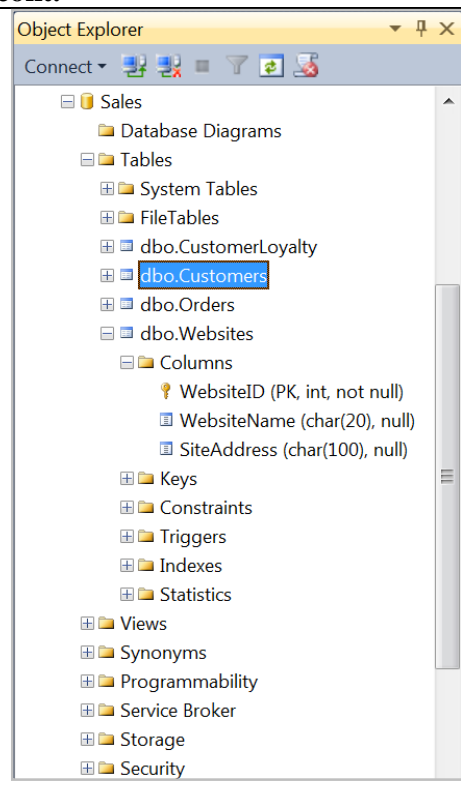

\section{Populate the Customers and Websites Tables}

In the Query Editor Window, enter and execute the following Insert Statements to add data to the Customers and Websites tables.

INSERT INTO Customers VALUES(10, 'Customer A', 'New York', 'NY');

INSERT INTO Customers VALUES(20, 'Customer B', 'Boston ', 'MA');

INSERT INTO Customers VALUES(30, 'Customer C', 'Philadelphia', 'PA');

INSERT INTO Customers VALUES(40, 'Customer D', 'San Francisco', 'CA');

INSERT INTO Customers VALUES(50, 'Customer E', 'Denver', 'CO');

INSERT INTO Customers VALUES(60, 'Customer F', 'Seattle', 'WA');

INSERT INTO Customers VALUES(70, 'Customer G', 'Las Vegas', 'NV');

INSERT INTO Customers VALUES(80, 'Customer H', 'Cleveland', 'OH');

INSERT INTO Customers VALUES(90, 'Customer I', 'Miami', 'FL');

INSERT INTO Customers VALUES(100, 'Customer J', 'Phoenix', 'AZ');

INSERT INTO Websites VALUES(1, 'Retailer A', 'www.shopping.com');

INSERT INTO Websites VALUES(2, 'Retailer B', 'www.buystuff.com');

INSERT INTO Websites VALUES(3, 'Retailer C', 'www.goods.net');

INSERT INTO Websites VALUES(4, 'Retailer D', 'www.retailer.com');

INSERT INTO Websites VALUES(5, 'Retailer E', 'www.stores.net');

\section{Figure 4: Populating Tables}




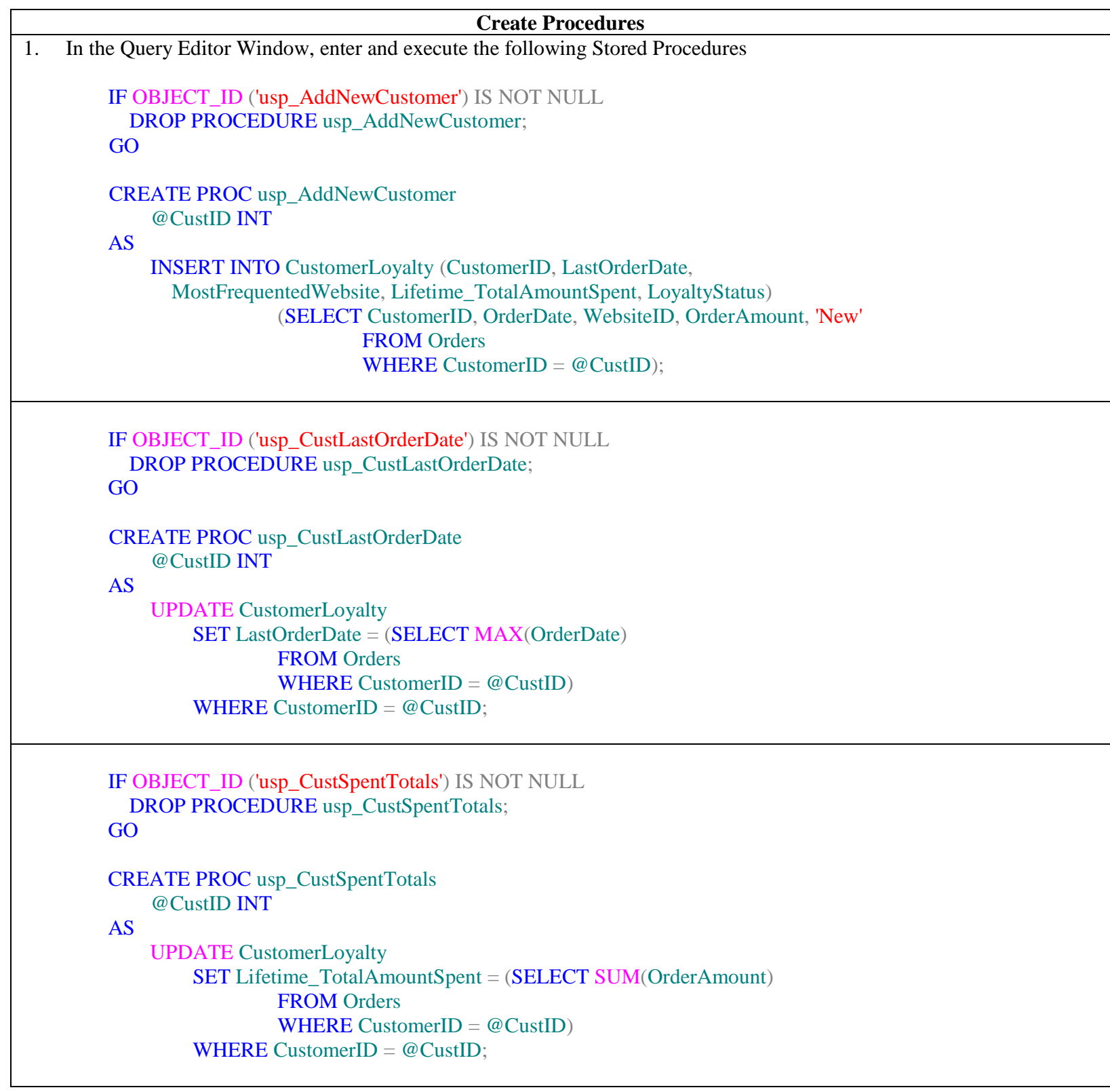

Figure 5: Creating Procedures 


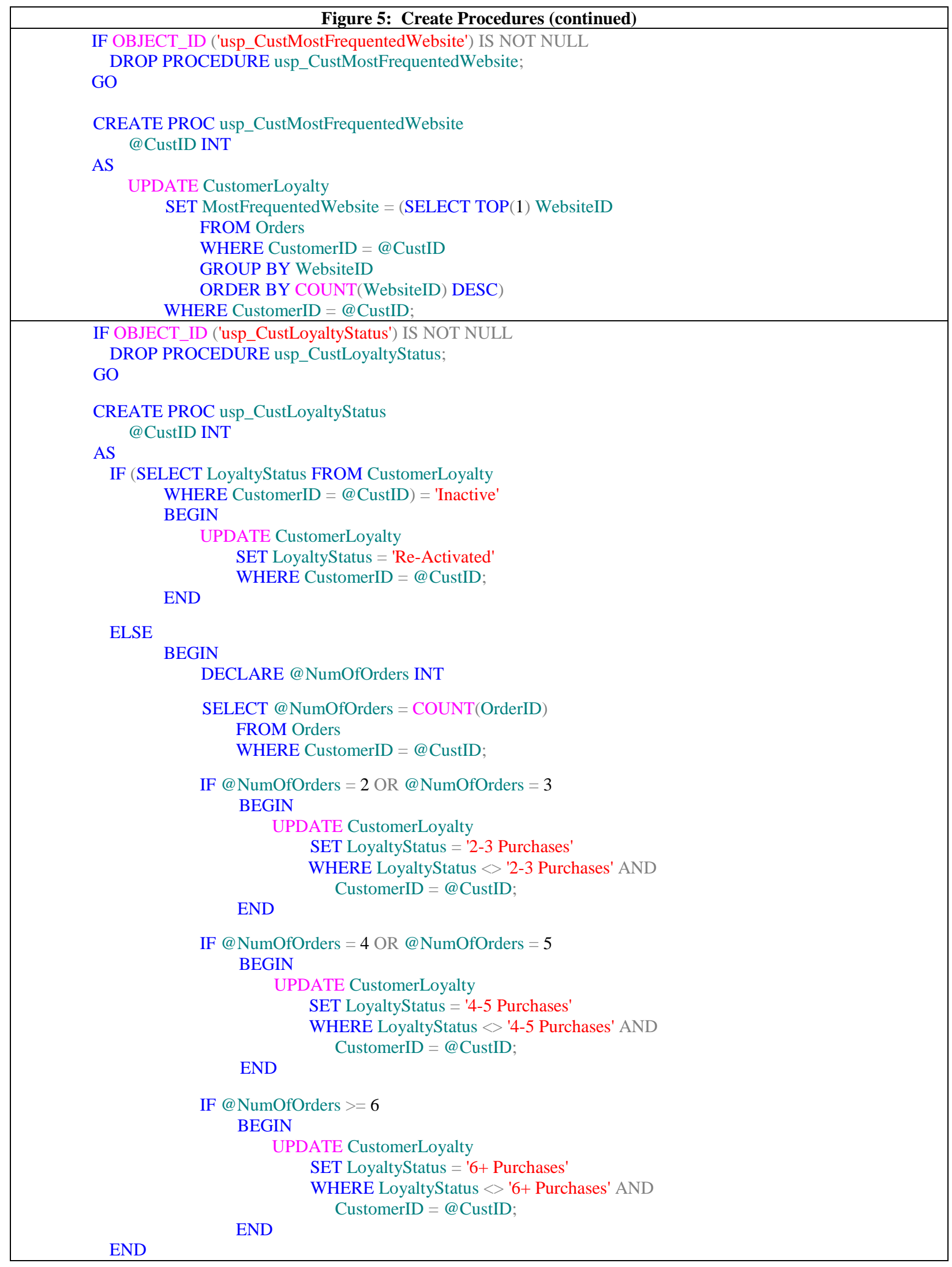




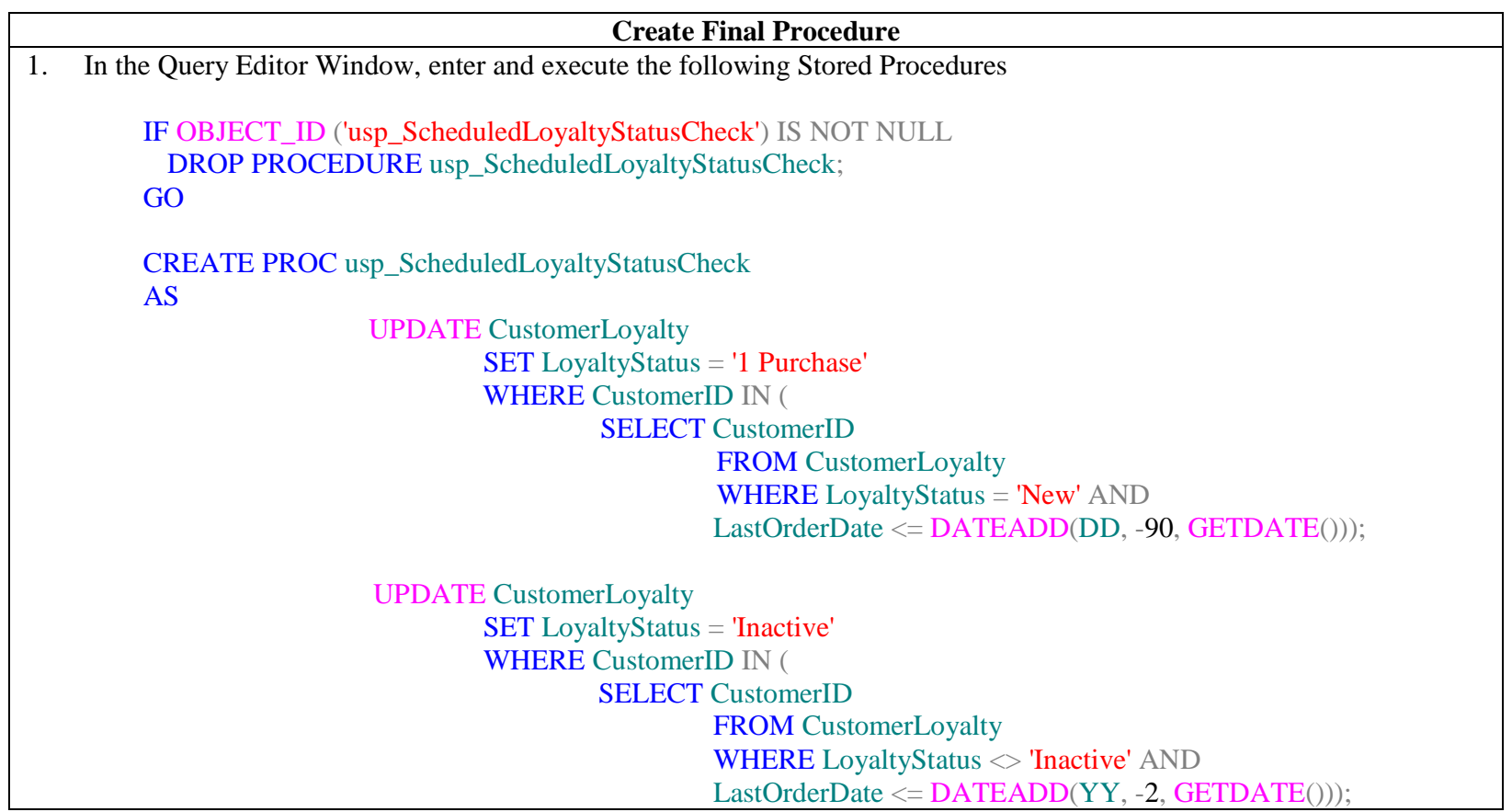

Figure 6: Creating Final Procedure 


\section{NOTES}

